RUNNING HEAD: MEMORY PERSPECTIVE

\title{
Switching Memory Perspective
}

\author{
Shazia Akhtar ${ }^{1}$, Lucy V. Justice ${ }^{2}$, Catherine Loveday ${ }^{3} \&$ Martin A. Conway $^{1}$ \\ ${ }^{1}$ Centre for Memory and Law, Department of Psychology, City, University of London \\ ${ }^{2}$ Department of Psychology, Nottingham Trent University \\ ${ }^{3}$ Department of Psychology, Westminster University
}

\begin{abstract}
Corresponding author:
Dr. Shazia Akhtar

Department of Psychology,

City, University of London,

The Rhind Building,

Northampton Square,

London, EC1V OHB

Email: $\underline{\text { Shazia.Akhtar@city.ac.uk }}$
\end{abstract}

Monday, 25 ${ }^{\text {th }}$ September, 2017 


\begin{abstract}
The perspective in which memories were spontaneously recalled, field (original perspective) or observer (see oneself in the memory), was examined for both recent and remote memories. Recent memories were dominated by field perspective whilst remote memories were dominated by observer perspective. Further, field memories contained reliably more episodic detail than observer memories. After a 1-week interval, the same memories were recalled again but with a switched memory perspective. Switching from an observer to a field perspective did not reliably increase the amount of episodic details in a memory. Switching from field to observer perspective did, however, reliably reduce the number of episodic details. These findings suggest that memories may be represented in longterm memory with a fixed perspective, either field or observer, which can be temporarily altered sometimes changing the nature of a memory, i.e. how much detail remains accessible.
\end{abstract}

Key terms: early memories, remote memories, memory perspective; field memories, observer memories, vantage point 
In one of the first ever surveys of human memory Henri and Henri (1898) noted that some of their respondents occasionally described seeing themselves in their memories, a phenomenon later described by Freud (1915) as being indicative of a memory that had been 'edited' or recoded. Nigro and Neisser (1983) revived interest in memory perspective and introduced the terms 'field' and 'observer' perspectives to denote respectively: a memory that preserves something approximating to a person's original point-of-view during the experience that is remembered or, alternatively, a memory in which the person sees or observes him/herself. The perspective experienced when a memory initially comes to mind is thought to arise non-consciously and unintentionally, although this perspective is not necessarily stable during extended recall of the same memory and may change as the remembered event unfolds (Bernsten \& Rubin, 2006; Rice \& Rubin, 2009). Others have also pointed out that perspective can be intentionally changed and that rememberers can switch back and forth between perspectives (Robinson \& Swanson, 1993).

A number of studies have revealed that field perspective is more common than observer perspective, with only a minority of memories recalled with an observer perspective (Nigro \& Neisser, 1983; Rice \& Rubin, 2011). Nigro and Neisser (1983) proposed several factors that may contribute to the determination of memory perspective, in particular the age of the memory: recent experiences are more likely to be remembered from a field perspective and older events from an observer perspective. This is now a well-established finding (Frank \& Gilovich, 1989; Kihlstrom \& Harackiewicz, 1982; Rice and Rubin, 2009; Sultin \& Robins, 2009;). Field perspective memories also predominate for experiences that were emotional at the time of their encoding (D’Argembeau et al., 2003; LaBar, \& Rubin, 2004; Strongman \& Kemp, 1991). However, Robinson and Swanson (1993) found that emotionality can be influenced by manipulating the perspective. Participants were asked to recollect 
autobiographical events from various times in their lives, to classify each memory as either 'field' or 'observer' and rate its emotional intensity on two levels - how the event made them feel when it took place and how they felt about it at recollection. One week later, participants recalled the same events a second time - either from the original vantage point or from the alternative perspective - and again rated their past and present emotional intensity. Although there was little change in the ratings of original and current emotionality when the vantage point remained constant or when it shifted from observer to field, there was a marked decrease in both measures when the perspective was switched from field to observer. As Schacter (1996) has remarked, these results suggest that not only does the emotional intensity of an event depend in part on how one goes about remembering it, but also the emotions one attributes to the past sometimes arise from the way in which memories are retrieved in the present.

Field perspective memories are, then, associated mostly with a feeling of reexperiencing the phenomenological features of the original event, accompanied by a high degree of vividness and recollective experience. Further, specific and detailed memories are more likely to be recalled with field perspective. In contrast, observer memories contain more descriptive detail but less sensory and emotional information (Berntsen \& Rubin, 2006; D’Argembeau et al., 2003; McIsaac \& Eich, 2002, 2004; Nigro \& Neisser, 1983; Sutin \& Rubin, 2010), typically have longer retention intervals (e.g, Nigro \& Neisser, 1983; Rice, Talarico, \& Rubin, 2005; Robinson \& Swanson, 1993), and higher levels of self-awareness or self-evaluation are reported as being present in the original experience (Frank \& Gilovich, 1989; Libby \& Eibach, 2002; Nigro \& Neisser, 1983). However, individuals reporting disorders such as social anxiety or body dysmorphic disorder report memories from an observer perspective that are highly vivid and emotionally intensive (Hackmann, Clark, \& 
McManus, 2000; Hackmann, Surawy, \& Clark, 1998; , Hackmann, \& Veale, 2004; Osman, Cooper Wells, Clark, \& Ahmad, 1998). Observer memories may also be associated with personality factors, for example, McIsaac and Eich (2004) found that the observer perspective predominates when publicly self-conscious individuals recollect their social interactions (see also Robinson \& Swanson, 1993) or when people high in 'harm avoidance' (characterised by excessive worrying, pessimism, shyness, being fearful, and easily fatigued) recall their earliest autobiographical experiences (Kihlstrom \& Harackiewicz, 1982). Related to this, situations involving a high degree of self-awareness, social anxiety, or physical threat (e.g., speaking in public, running from danger) give rise to more observer than field recollections (Nigro \& Neisser, 1983). Finally, instructions to concentrate on the objective circumstances surrounding an event often evoke memories with an observer perspective, whereas asking people to focus on the feelings associated with the original event typically elicits memories recalled with a field perspective (Nigro \& Neisser, 1983).

The aim of the present study was to investigate whether switching memory perspective would give rise to the characteristics associated with the altered perspective. For example, if a memory originally and spontaneously recalled with an observer perspective was switched to a field perspective, would the changed perspective give rise to a memory with more specific details? And, conversely, if a memory originally recalled with a field perspective was subsequently recalled with an observer perspective, would this result in fewer reportable details, particularly of emotions and feelings? These questions about the effects of changing perspective are important, given that police officers commonly believe that if they recreate the original encoding environment during an interview (a sort of super-field perspective) this will enhance a victim's memory and their ability to retrieve of specific details (Wells, Morrison, \& Conway, 2011). The cognitive interview (CI; Fisher \& Geiselman, 1992) is a 
questioning technique used by police to enhance retrieval of information from witnesses. This approach is now one of the most widely used and accepted forms of interviewing in both the US and the UK (Fisher \& Geiselman, 1992; Geiselman, 1984), and is currently taught to police recruits in the UK (Dando \& Milne, 2009). The CI has been shown to elicit detailed, yet accurate, reports from adult witnesses (Davis, McMahon, \& Greenwood, 2005; Kohnken, Milne, Memon, \& Bull, 1999), children (Geiselman \& Padilla, 1988; Memon, Wark, Bull, \& Koehnken, 1997), and older witnesses (Wright \& Holliday, 2007b). We suggest that, at least in part, the CI may powerfully reinstate a field perspective and, possibly in this way, enhance recall of details.

In the present study participants were instructed to recall six early and six recent memories. In each case, they were asked to state the perspective with which the memory was recalled and asked to provide subjective recollective measures such as vividness, emotional intensity and personal importance. Previous studies (Nigro \& Neisser, 1983; Robinson \& Swanson, 1993) have found that early memories are predominantly recalled with an observer perspective whilst recent memories are predominantly recalled with a field perspective. Asking participants to provide memories from both of these age groups in the current study allowed for this to be tested and controlled for. The recollective measures were recorded in order to investigate whether perspective switching would alter the qualitative nature of the memories. One week later, participants were cued to recall the same memories again but instructed to switch the memory perspective. They were asked to provide the same recollective measures as at time 1 . We expected that when the switch was from field to observer that fewer episodic details would be recalled relative to the first, field-perspective, memory. However, when the switch was from an observer perspective to a field perspective memory we expected that more episodic details would be recalled in the second recall 
relative to the first observer-perspective recall, i.e. memory would be enhanced. Further, in line with current literature (Nigro \& Neisser, 1983; Rice \& Rubin, 2011) we expected memories recalled with a field perspective to be reliably more vivid, personally important and emotionally intense as compared to memories recalled with an observer perspective. We expected that when participants switched from field to observer perspective, these three variables would be rated reliably lower. Relatedly, when the switch was from an observer perspective to a field perspective memory we expected these three variables to be rated as reliably higher. Such a pattern of findings would, in several ways, lend support to the CI and to investigator-interviewing practices.

\section{Method}

\section{Participants}

There were thirty-three females and two males, with a mean age of $21.5(S D=8.74)$ years, recruited from the general population. Participants were tested in small groups or individually in the laboratory. Participants completed the two sessions in the same way, such that if they were tested in small groups in session one, they were also tested in the same small group in session two. Participants received a small honorarium or, if they were students, course credits. All participants spoke English as their first language.

\section{Materials and procedure}

The study was conducted in two sessions. In the first part of the study, time 1 (t1) participants completed a questionnaire. The questionnaire began with an information page outlining key instructions regarding the nature of the memories to-be-sampled, and collected 
minimal demographic data (age, gender and whether English was their first language). Respondents were also informed that after recalling their memories they would be asked to answer some questions about the memory. For these questions they were instructed not to guess or infer but to only respond if they actually remembered the answer.

Participants then moved to the next page of the questionnaire proper. They were instructed to recall and then write a title and description (in the box provided) of an early memory (before the age of 10) or a recent memory (1-5 years ago). Participants had to recall a total of six early memories and six recent memories. The order of age of memory was counterbalanced. The title was to be only a few words in length but of sufficient specificity that if it was read again it would serve as a reminder of the to-be-recalled memory. The memory description was to be about a paragraph or so in length. The memory itself had to be one that the participant was certain they remembered, not based on, for example, a family photograph, family story, or any source other than direct experience. The memory had to be for a specific one-off event that lasted no longer than minutes/hours. It was specifically emphasised that the memory should not be of a routine or repeated event. After entering the title and memory description participants then answered the following questions: (1) is the memory seen from the field (approximating your original point-of-view) or from an observer perspective in which you 'see' yourself in the memory, or from neither perspective? (2) How vivid is the memory? (vividness) (3) How intense was your emotional response to the memory? (emotionality) (4) How important has this event been for you personally? (personal importance) (5) How old were you when the remembered event happened (to the nearest year)? Questions 2, 3, and 4 were answered by checking a box on a 5-point scale where $1=$ low, $3=$ moderate, and $5=$ high, intermediary numbers were used to garner finer-grained answers. 
In part two of the experiment, time 2 (t2) one week later, participants were presented with another questionnaire. Again, the questionnaire began with an information page outlining key instructions. In a random order, participants were presented with the memory titles they had provided one week earlier. Participants were instructed to recall the memory, but were given a perspective from which to recall it (always the opposite to the original perspective). On the next page of the booklet the first memory title appeared. Participants then answered the following questions about their memory: (1) How difficult did you find writing this memory? This was on a 3-point scale $(1=$ not very difficult, $3=$ very difficult $)$;

(2) Were you able to use the memory perspective specified? Participants responded yes or no;

(3) In the past week how often have you thought about this memory? (Note this question was included to assess the amount of rehearsal the memory had received between test sessions):

(4) Did you recall a) the memory, b) your previous description, c) mix of a and b; (5) Overall how vivid is this memory?; (6) Overall, how intense was your emotional response to the memory?; (7) How important has this event been for you personally? Questions 3, 5, 6, and 7 were answered by checking a box on a 5 -point scale where $1=$ low, $3=$ moderate, and $5=$ high, intermediary numbers were to use for more fine-grained answers.

Results

\section{Qualitative aspects of the memories}

There were 396 memories in total. Recent memories could be broadly classified into several categories, including memorable birthday (43\%), a particular exam (26\%), a memorable holiday (13\%), occasion/birth of a relative/achievements (18\%). Early memories included categories such as illness/injury (24\%), birth of a relative (30\%), holiday trips and birthdays (46\%). The majority of the memories were everyday mildly positive memories. 


\section{Coding of memory details}

All memories were coded by the first author. Interrater reliability was assessed using a subset of 50 coded memories from the database. These were coded by an independent coder, who was not aware of any other aspect of the research. The linguistic content of each memory was analysed by categorising every detail, determining whether it was related to an action, place, people, a sensory-perspective detail, affect, cognition, time sign or an object (Loveday \& Conway, 2011). Correlating the coding produced by the first author and independent coder showed consistency across all categories, (actions $r=.71, p<.001$; people $r=.75, \mathrm{p}<.001 ;$ place $r=.92, p<.001$; sensory-perspective detail, affect, cognition, time and sign and object had a mean correlation of $r=.86, p<.001)$.

Analyses

Unless otherwise stated, data were analysed using linear mixed effects models in order to account for the hierarchical structure (multiple memories nested within each participant). The analyses were conducted using RStudio Version 0.99.89 (RStudio Team, 2015), 1me4 (Bates, Maechler, \& Bolker, 2012) and Ordinal (Christensen, 2015). Fixed effects differed depending on the specific analysis, however 'participant' was entered as a random effect in all models. All generated models were compared with a null model (a model with a constant in place of fixed effects) and $p$-values were obtained using likelihood ratio tests.

\section{Memories at Time One}

Of the 396 memories that were generated at time one, 198 were rated as recent memories and 198 as early memories. A linear mixed effect model with memory age included as a fixed effect showed that recent memories contained reliably more episodic 
detail $(M=13.93 . S D=8.09)$ than early memories $(M=16.07, S D=8.06),\left(X^{2}(1)=11.15, p\right.$ $<.001)$. Ordinal mixed effects models with memory age as fixed effect showed that recent memories were also rated higher in vividness $(M=4.24, S D=0.91),\left(X^{2}(1)=78.34, p<\right.$ $.001)$ and emotional intensity $(M=3.73, S D=1.05),\left(X^{2}(1)=39.11, p<.001\right)$ than early memories (vividness $M=3.37, S D=1.12$, emotional intensity $M=3.13, S D=1.12$ ). However, these differences may be accounted for by the fact that recent memories were reliably higher in personal importance $(M=3.61, S D=1.17)$ than early memories $(M=2.83$, $S D=1.29),\left(X^{2}(1)=44.93, p<.001\right)$. Turning to proportions of perspective as a function of memory age, we expected participants to have more field perspectives for recent memories and have more observer memories for early memories, following Freud (1974) and Nigro and Neisser (1983). A binomial mixed effects model revealed a reliable difference in perspective as a function of memory age $\left(X^{2}(1)=45.88, p<.001\right)$. The probability of recent memories being recalled with a field perspective was $90.1 \%$ and the probability of recent memories being recalled with an observer perspective was $9.9 \%$. Conversely, the probability of an early memory being recalled with a field perspective was $39.7 \%$ and probability of recall with an observer perspective was $60.3 \%$. Note, there were no participants who reported they could not decide a memory perspective.

Table 1 about here

An ordinal logistic mixed effects model was applied to the data with recollective measures entered in separate models as the fixed effect. Results revealed that field memories were more vivid $\left(X^{2}(1)=51.29, p<.001 ; M=4.04, S D=1.02\right.$ vs $\left.M=1.87, S D=1.01\right)$; emotionally intense $\left(X^{2}(1)=36.03, p<.001 ;(M=3.66, S D=1.04\right.$ vs $M=3.44, S D=1.01)$ 
and personally important $\left(X^{2}(1)=34.86, p<.001 ; M=3.46, S D=1.8\right.$ vs $M=3.19, S D=$ 1.04), compared to observer memories.

\section{Memories at Time Two}

Across both perspectives, most participants rated writing the memory as 'easy'. An ordinal logistic mixed effects analysis showed that difficulty in writing did not differ between perspectives $\left(X^{2}(1)=.81 \mathrm{p}=.37\right)$. Over both perspectives, $79.67 \%$ of respondents said they were able to change perspective and $20.33 \%$ stated they could not change perspective. When asked to switch perspective from observer to field, $78.9 \%$ of participants said they could change perspective and $21.1 \%$ said they could not. When asked to switch perspective from field to observer, $80 \%$ said they were able to do so and $20 \%$ said they were not. There were no reliable differences in the ability to change perspective as a function of original perspective taken $\left(X^{2}(1)=36.55, \mathrm{p}<.06, p=.81\right)$. Memories in which participants stated they were unable to change perspective were omitted from the analysis. When asked how often the memory was thought about, $94.2 \%$ of respondents reported less than three times in the week. However, $2.2 \%$ of respondents reported more than four times in the week and $3.6 \%$ of respondents did not respond to the questions. Therefore these memories were removed from the analysis as they had been highly rehearsed or their rehearsal frequency was unknown. Finally, when asked about the recall of memory, $92.3 \%$ of participants recalled the actual memory, $1.8 \%$ of respondents recalled the previous description (these memories were removed from the analysis), $2.6 \%$ of respondents recalled a mix of the memory and description and $3.3 \%$ of respondents did not respond to the question (these memories were also removed from the analysis).

For the remaining results we grouped recent and early memories together. Memories were contrasted across time one and time 2 and our analyses focused on differences in 
episodic detail and recollective qualities between observer and field perspectives. There are five analyses reported:

1. Field $\mathrm{t} 1(\mathrm{Ft} 1)$ switched to Observer $\mathrm{t} 2(\mathrm{O}(\mathrm{F}) \mathrm{t} 2$

2. Observer $\mathrm{t} 1(\mathrm{Ot} 1)$ switched to Field $\mathrm{t} 2(\mathrm{~F}(\mathrm{O}) \mathrm{t} 2$

3. Field $\mathrm{t} 1(\mathrm{Ft} 1)$ contrasted with Field (originally Observer) $\mathrm{t} 2(\mathrm{~F}(\mathrm{O}) \mathrm{t} 2$

4. Observer $\mathrm{t} 1(\mathrm{Ot} 1)$ contrasted with Observer (originally Field) t2 (O(F)t2;

5. Field t2 (originally observer) contrasted with Observer t2 (originally field).

\section{Field $t 1(F t 1)$ switched to Observer t2 $(O(F) t 2$}

We were primarily interested to see the pattern of episodic details after instructing participants to switch memory perspectives. A linear mixed effects analysis revealed more overall episodic details in field $\mathrm{t} 1$ (Ft) memories than after the memories had been switched to an observer perspective. There were also reliable differences in the number of action, places, people, sensory-perspective detail, affect, cognition and time and sign in Ft1 memories (see row 1, table 2). Ordinal logistic mixed effects analyses were performed to further assess vividness, emotional intensity and personal importance across memories at time 1 and 2. The analysis showed that memories recalled with a field perspective were reliably more vivid $\left(X^{2}(1)=359.94, \mathrm{p}<.001 ; M=4.06, S D=1.02\right.$ vs $\left.M=1.87, S D=1.04\right)$; emotionally intense $(M=3.66, S D=1.08$ vs $M=2.65, S D=1.01)$ and personally important $\left(X^{2}(1)=7.92, p<.005 ; M=3.46, S D=1.25\right.$ vs $\left.M=3.19, S D=1.06\right)$ as compared to memories switched from field to an observer perspective.

\section{Observer $11(\mathrm{Ot} 1)$ switched to Field t2 $(F(O) t 2)$}

A linear mixed effects model revealed that more episodic details were recalled for memories recalled with an Observer perspective at t1 (Ot1), compared to after they had been switched to a Field perspective at t2 $(F(O) t 2)$. Moreover, there were more actions, places, 
people, sensory-perspective detail, time and sign and object details recalled in Ot1. There were no reliable differences in affect and cognition (see row 2, table 2). Ordinal logistic mixed effects analyses revealed that memories recalled with an Observer perspective at $\mathrm{t} 1$ were reliably more vivid $X^{2}(1)=48.77, p<.001,(M=3.22, S D=1.15)$ than memories that had been switched to a field (observer) perspective at $\mathrm{t} 2,(M=2.14, S D=0.94)$. There were no reliable differences in emotional intensity or personal importance.

\section{Field $t 1$ (Ft1 contrasted with Field (Observer) $t 2(F(O) t 2$}

Memories recalled with a field perspective at time 1, had more episodic details compared to memories that had been switched to a field perspective at time 2. Specifically, there were reliable differences in overall episodic details, and across all the episodic details (see row 3, table 2). Ordinal logistic mixed effects analysis was performed to assess vividness, emotional intensity and personal importance across time. The analysis showed that memories recalled with a field perspective at time 1 were reliably more vivid $\left(X^{2}(1)=\right.$ $149.18, p<.001, M=4.06, S D=1.01$ vs $M=2.18, S D=1.02)$; emotionally intense $\left(X^{2}(1)=\right.$ $36.03, p<.001, M=3.66, S D=1.08$ vs $M=2.9, S D=1.2)$; and personally important $\left(X^{2}(1)\right.$ $=36.55, p<.001, M=3.46, S D=1.25$ vs $M=2.65, S D=1.02)$ than memories that had been switched to a field perspective at time 2.

\section{Observer $t 1(O t 1)$ contrasted with Observer (Field) $t 2(O(F) t 2$}

A comparison of memories that had been recalled with an observer perspective at time 1 with memories that had been switched to an observer perspective at time 2 revealed that there were more overall episodic details recalled for time 1 than time 2 . However, when turning to the analysis of recollective detail, results showed that there were only reliable differences for affect and cognition (see row 4, table 2). An ordinal logistic mixed effects analysis showed that memories that had been switched to an observer perspective at time 2 
were reliably more vivid $\left(X^{2}(1)=72.79, p<.001, M=3.22, S D=1.15\right.$ vs $M=1.87, S D=$ $1.2)$; emotionally intense $\left(X^{2}(1)=20.31, p<.001, M=3.44, S D=1.03\right.$ vs $M=2.9, S D=$ $1.2)$; and personally important $\left(X^{2}(1)=36.55, p<.001, M=3.19, S D=1.2\right.$ vs $M=2.65, S D$ $=1.18$ ) than memories that had been originally recalled with an observer perspective at time 1.

\section{Field t2 (originally observer) contrasted with Observer 2 (originally field)}

When comparing memories that had had their perspectives switched at time 2, we found no reliable differences for episodic details (see row 5, Table 2). Memories switched to an observer perspective at time 2 were found to be more vivid $\left(X^{2}(1)=3.32, p<.001, M=\right.$ $3.46, S D=1.14$ vs $M=2.65, S D=1.2)$; emotionally intense $X^{2}(1)=17.05, p<.001, \mathrm{M}=$ $3.44, S D=1.03$ vs $M=2.9, S D=1.2)$ and personally important $X^{2}(1)=20.61, \mathrm{p}<.001, \mathrm{M}=$ $3.19, S D=1.2$ vs $M=2.65, S D=1.18)$ than memories that had been switched to a field perspective at time 2 .

Table 2 about here

\section{Discussion}

Confirming previous findings, we found that early (childhood) memories were dominated by observer perspective in contrast to recent memories that were dominated by field perspective (Nigro \& Neisser, 1983; Robinson \& Swanson, 1993). Field memories were found to be rich in episodic details, vivid, emotionally intense, and personally important compared to observer memories, which were reliably less rich in episodic detail, and not as 
vivid, intense, or personally important. We assume that all memories are initially encoded in long-term memory with a field perspective, with the possible exception of memories encoded during altered states of conscious, i.e. during trauma and/or intoxication. The present findings clearly suggest then that older memories, and some recent memories spontaneously recalled with observer perspective, have undergone some sort of recoding. As none of the memories recalled in this study indicated any altered states of consciousness they must then have been recoded from field to observer perspective and are now spontaneously recalled with the recoded observer perspective. As field memories contain more episodic details than observer memories this recoding process might be thought of as a type of forgetting in which some episodic detail is lost. Possibly, observer memories are a more efficient form of storage in long-term memory because they contain fewer details, and over time, consolidation processes seek to recode most memories into an observer perspective. Why this does not take place for all memories is unclear but it may be that vividness, emotionality, and importance render some memories immune to such recoding. On the other hand, even recent memories lower in these qualities may be more rapidly recoded into observer perspective. Furthermore, Eich et al. (2011) propose emotionally negative vivid memories are often recalled with an observer perspective. They further suggest observer perspective may facilitate emotional regulation and emotional distancing from the event, suggesting that the psychological and physical pain of reliving an aversive experience can be attenuated by recalling the event from the eyes of a dispassionate observer (Benson, McGeeney, Brown, \& Albert, 2005; D’Argembeau \& van der Linder, 2004; McNamara, Williams \& Mould, 2007; Wilson \& Ross, 2003).

It is clear that people can change memory perspective and imagine seeing themselves in a memory or imagine something approximating to their original view. Intentionally manipulating memories in consciousness appears to an ability many people have. For example, intentionally imagining false details in an otherwise 'true' memory is something 
many people find relatively easy (Justice, Morrison, \& Conway, 2013). Perhaps many acts of imagery-based memory manipulation are undertaken spontaneously in everyday thinking, i.e. imaging how an experience might have had an alternative outcome, or how one might have acted differently, and of course imaging future events based on memories of previous experiences. Indeed, Conway, Loveday, and Cole (2016) suggested the term the remembering-imaging system (rather than just 'memory') to highlight how memory supports imagining. Thus, switching memory perspective is one of several ways in which memories can be manipulated by imagination. When switching memory perspective from field to observer in the present study it was found that most participants were able to successfully construct an observer memory, one that had less episodic details, and was not as vivid, intense or personally important as the original field memory. However, when switching an observer memory, originally and spontaneously recalled with an observer perspective, to a field memory, the memory now with a field rather than observer perspective, was not rich in episodic details, and there were no differences in intensity or personal importance. In other words, although for the rememberer the memory perspective has changed, the qualities of the memory were not those of a field memory. By the above reasoning this is because the memory has been recoded in long-term memory into an observer memory and even though by an act of imagination the perspective can be changed, this does not reinstate all the episodic detail originally encoded in long-term memory. Thus changing to a field perspective will not increase the recall of episodic details, as some have suggested (Fisher \& Geiselman, 2010).

This finding is important because it clearly shows that switching perspective, from observer to field, does not enhance memory for episodic details nor does it enhance the recollective qualities of a memory which remain at a level lower than that associated with memories spontaneously recalled with a field perspective. This has implications for 
interviewing techniques that attempt to improve recall using field perspectives, such as those used by the police or in clinical settings (e.g., psychotherapy, reliving in cognitive behavioural therapy [CBT]): although it is possible to change perspective, this act does not alter other qualities of the (originally observer perspective) memory. However, this limitation may only apply to memories of emotionally positive memories such as those recalled in the present study, and it may be the case that memories of emotionally negative experiences - the type of memories that police and clinicians typically deal with - would show a different pattern. One possibility is that memories of negative experiences are initially represented in long-term memory with both perspectives but are typically retrieved with an observer perspective. Possibly, as others have suggested (Freud, 1915; Nigro \& Neisser, 1983), such a retrieval bias serves the purpose of protecting the rememberer from potentially destabilising negative emotions triggered by the memory. If this were the case, then guided protracted retrieval attempts aimed at accessing a field perspective representation of a memory might indeed lead to increased recall of more detail, heightened emotion, and enhanced memory vividness.

Related to this Conway, Meares, and Standart (2004) described the case of a posttraumatic stress (PTSD) patient who was present during the 9/11 terrorist attack in New York. This patient had an intrusive memory of seeing himself flying in peaceful silence above the first plane to strike. In reality he had been on the ground in a group of terrified onlookers. In his CBT reliving treatment, he eventually came to recall being in the group of onlookers and as this was achieved so his levels of PTSD diminished. Memory intrusiveness was markedly reduced, to something similar to that of a more typical memory of an emotionally negative experience. Interviewed after his recovery he claimed to now have both memories, one of seeing himself flying, and the other of being on the ground watching the 
plane strike the tower: the former an observer memory with the qualities of such a memory and the later a field memory also with the qualities of a field memory.

The present findings show that changing from an observer to a field perspective, at least for memories of mildly positive everyday experiences, does not instate other field memory qualities, i.e. greater recall of details and raised affect. On the other hand, changing perspective from field to observer does instate observer memory qualities, i.e. lower recall of details, reduced emotion and vividness. Thus, changing to observer perspective essentially reduces both the quantity, quality and intensity of recollected experience. We suggest, then that observer memory perspective memory, is a type of forgetting and may be common for memories of emotionally mild everyday experiences with lengthy retention intervals: in short, it is what these memories become as the retention interval increases. Memories with observer perspective may be a more information-efficient form of representation in long-term memory. In contrast memories of emotionally intense experiences, especially negative experiences, may retain their field perspective for longer periods of time and, possibly, have dual representations as both field and observer memories in long-term memory. 


\section{References}

Bates, D., Maechler, M., Bolker, B., \& Walker, S. (2015). Fitting Linear Mixed-Effects Models Using lme4. Journal of Statistical Software, 67(1), 1-48.

Berntsen, D., \& Rubin, D. C. (2006). Emotion and vantage point in autobiographical. Cognition and Emotion, 20(8), 1193-1215.

Butler, A. C., Rice, H. J., Wooldridge, C. L., \& Rubin, D. C. (2016). Visual imagery in autobiographical memory: The role of repeated retrieval in shifting perspective. Consciousness and Cognition, 42, 237-253.

Christensen, R. H. B. (2015). Ordinal - Regression Models for Ordinal Data. R package version 2015.6-28. http://www.cran.r-project.org/package=ordinal/

Conway, M. A., Loveday, C., \& Cole, S. N. (2016). The remembering-imagining system. Memory Studies, 9(3), 256-265.

Conway, M., Meares, K., \& Standart, S. (2004). Images and goals. Memory, 12(4), 525-531.

D’Argembeau, A., \& Van der Linden, M. (2004). Phenomenal characteristics associated with projecting oneself back into the past and forward into the future: Influence of valence and temporal distance. Consciousness and Cognition, 13(4), 844-858.

Eich, E., Handy, T. C., Holmes, E. A., Lerner, J., \& McIsaac, H. K. (2012). Field and observer perspectives in autobiographical memory. Social Thinking and Interpersonal Behavior, 163-181.

Fair, D. A., Cohen, A. L., Dosenbach, N. U., Church, J. A., Miezin, F. M., Barch, D. M., ..., \& Schlaggar, B. L. (2008). The maturing architecture of the brain's default network. Proceedings of the National Academy of Sciences, 105(10), 4028-4032.

Fisher, R. P., \& Geiselman, R. E. (2010). The cognitive interview method of conducting police interviews: Eliciting extensive information and promoting therapeutic jurisprudence. International Journal of Law and Psychiatry, 33(5), 321-328.

Frank, M. G., \& Gilovich, T. (1989). Effect of memory perspective on retrospective causal attributions. Journal of Personality and Social Psychology, 57(3), 399.

Hackmann, A., Clark, D. M., \& McManus, F. (2000). Recurrent images and early memories in social phobia. Behaviour Research and Therapy, 38(6), 601-610.

Hackmann, A., Surawy, C., \& Clark, D. M. (1998). Seeing yourself through others' eyes: A study of spontaneously occurring images in social phobia. Behavioural and Cognitive Psychotherapy, 26(1), 3-12.

Justice, L. V., Morrison, C. M., \& Conway, M. A. (2013). True and intentionally fabricated memories. The Quarterly Journal of Experimental Psychology, 66(6), 1196-1203.

Kihlstrom, J. F., \& Harackiewicz, J. M. (1982). The earliest recollection: A new 
survey. Journal of Personality, 50(2), 134-148.

Kuyken, W., \& Moulds, M. L. (2009). Remembering as an observer: How is autobiographical memory retrieval vantage perspective linked to depression? Memory, 17(6), 624-634.

Lee, T., \& Geiselman, R. E. (1994). Recall of perpetrator height as a function of eyewitness and perpetrator ethnicity. Psychology, Crime and Law, 1(1), 11-19.

Libby, L. K., \& Eibach, R. P. (2002). Looking back in time: self-concept change affects visual perspective in autobiographical memory. Journal of Personality and Social Psychology, 82(2), 167.

McIsaac, H. K., \& Eich, E. (2002). Vantage point in episodic memory. Psychonomic Bulletin \& Review, 9(1), 146-150.

McNamara, P., Benson, E., McGeeney, B., Brown, A., \& Albert, M. L. (2005). Modes of remembering in patients with chronic pain: Relation to current pain. The Journal of Nervous and Mental Disease, 193(1), 53-57.

Nigro, G., \& Neisser, U. (1983). Point of view in personal memories. Cognitive Psychology, 15(4), 467-482.

Osman, S., Cooper, M., Hackmann, A., \& Veale, D. (2004). Spontaneously occurring images and early memories in people with body dysmorphic disorder. Memory, 12(4), 428436.

Peterson, C., Sales, J. M., Rees, M., \& Fivush, R. (2007). Parent-child talk and children's memory for stressful events. Applied Cognitive Psychology, 21(8), 1057-1075.

Rice, H. J., \& Rubin, D. C. (2009). I can see it both ways: First-and third-person visual perspectives at retrieval. Consciousness and Cognition, 18(4), 877-890.

Robinson, J. A., \& Swanson, K. L. (1993). Field and observer modes of remembering. Memory, 1(3), 169-184.

Rubin, D. C. (2006). The basic-systems model of episodic memory. Perspectives on Psychological Science, 1(4), 277-311.

Rubin, D. C., Dennis, M. F., \& Beckham, J. C. (2011). Autobiographical memory for stressful events: The role of autobiographical memory in posttraumatic stress disorder. Consciousness and Cognition, 20(3), 840-856.

Schacter, D. L. (1996). Illusory memories: a cognitive neuroscience analysis. Proceedings of the National Academy of Sciences, 93(24), 13527-13533.

RStudio Team (2015). RStudio: Integrated Development for R. RStudio, Inc., Boston, MA URL http://www.rstudio.com/.

Wells, A., Clark, D. M., \& Ahmad, S. (1998). How do I look with my minds eye: Perspective taking in social phobic imagery. Behaviour Research and Therapy, 36(6), 631-634. 
Wells, C., Morrison, C. M., \& Conway, M. A. (2014). Adult recollections of childhood memories: What details can be recalled? The Quarterly Journal of Experimental Psychology, 67(7), 1249-1261.

Williams, A. D., \& Moulds, M. L. (2007). Cognitive avoidance of intrusive memories: Recall vantage perspective and associations with depression. Behaviour Research and Therapy, 45(6), 1141-1153.

Wilson, A., \& Ross, M. (2003). The identity function of autobiographical memory: Time is on our side. Memory, 11(2), 137-149. 
Table 1. Count (and proportions) of early and recent memories recalled with a field and observer perspective

\begin{tabular}{lll}
\hline & Field & Observer \\
\hline Recent & $166(83.84 \%)$ & $32(16.16 \%)$ \\
Early & $113(57.07 \%)$ & $85(42.93 \%)$ \\
\hline
\end{tabular}


Table 2. Likelihood ratio test results, means and standard deviations for outcome measures per analysis conducted

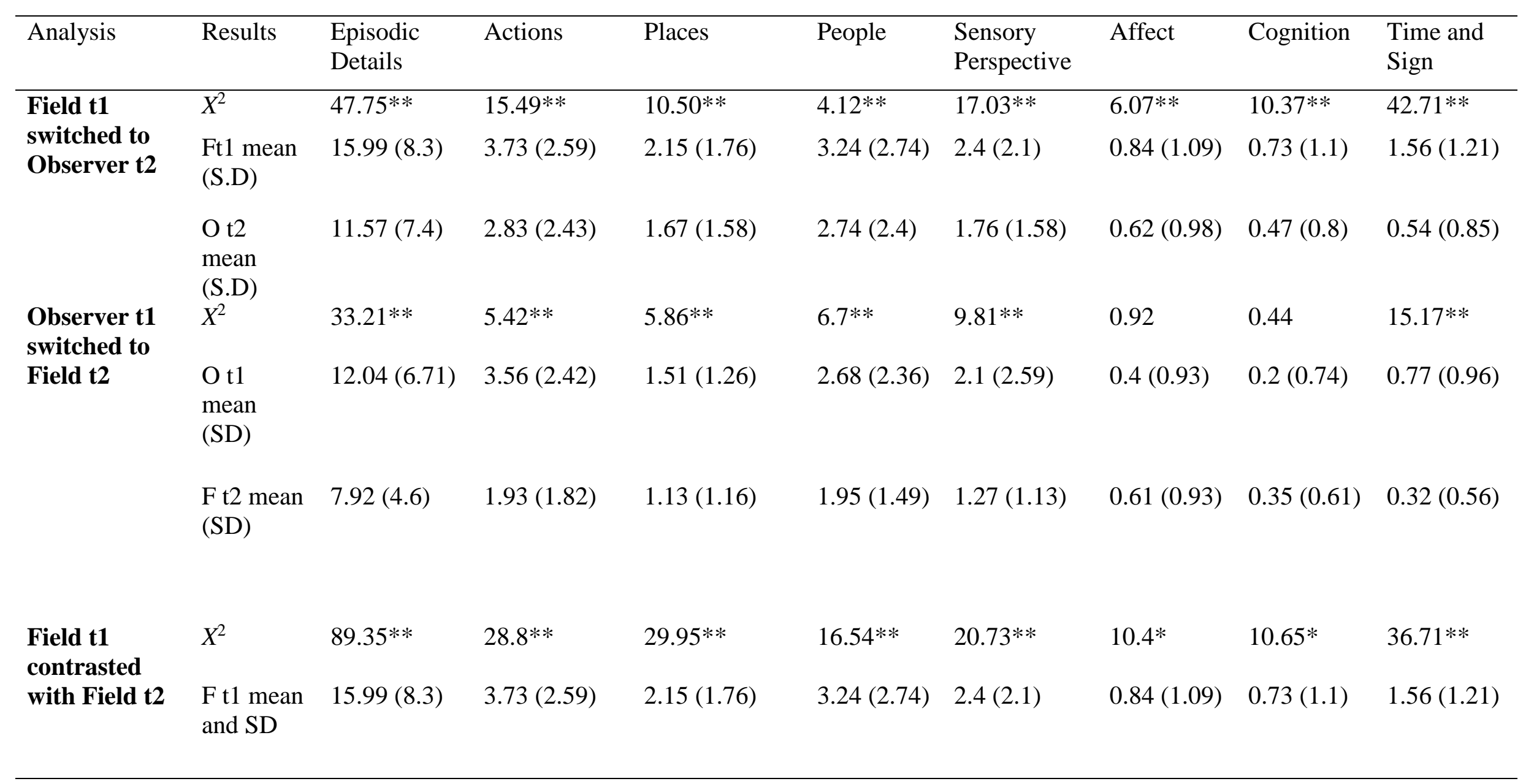




\begin{tabular}{|c|c|c|c|c|c|c|c|c|c|}
\hline & $\begin{array}{l}\mathrm{F} \text { t2 mean } \\
\text { and SD }\end{array}$ & $7.93(4.61)$ & $1.94(1.82)$ & $1.94(1.82)$ & $1.97(1.49)$ & $1.24(1.1)$ & $0.45(0.69)$ & $0.25(0.53)$ & $0.31(0.56)$ \\
\hline \multirow{3}{*}{$\begin{array}{l}\text { Observer t1 } \\
\text { contrasted } \\
\text { with } \\
\text { Observer t2 }\end{array}$} & $X^{2}$ & $6.87 *$ & 0.04 & 0.04 & 0.89 & $8.25^{*}$ & 0.75 & 0.03 & $3.88 *$ \\
\hline & $\begin{array}{l}\mathrm{O} \mathrm{t} 1 \\
\text { mean and } \\
\mathrm{SD}\end{array}$ & $12.04(6.71)$ & $3.56(2.42)$ & $1.51(1.26)$ & $2.68(2.36)$ & $2.1(2.59)$ & $0.4(0.93)$ & $0.2(0.74)$ & $0.77(0.96)$ \\
\hline & $\begin{array}{l}\mathrm{O} \text { t2 } \\
\text { mean and } \\
\mathrm{SD}\end{array}$ & $11.57(7.4)$ & $2.83(2.43)$ & $1.67(1.58)$ & $2.74(2.4)$ & $1.76(1.58)$ & $0.62(0.98)$ & $0.47(0.8)$ & $0.54(0.85)$ \\
\hline \multirow{3}{*}{$\begin{array}{l}\text { Field } \mathbf{t} 2 \\
\text { contrasted } \\
\text { with } \\
\text { Observer } \mathbf{t} 2\end{array}$} & $X^{2}$ & $8.85^{*}$ & 2.92 & 7.82 & 3.3 & 0.37 & 1.3 & 1.29 & 4.85 \\
\hline & $\begin{array}{l}\text { Field } \mathrm{t} 2 \\
\text { mean and } \\
\mathrm{SD}\end{array}$ & $7.92(4.6)$ & $1.93(1.82)$ & $1.13(1.16)$ & 1.95 (1.49) & $1.27(1.13)$ & $0.61(0.93)$ & $0.35(0.61)$ & $0.32(0.56)$ \\
\hline & $\begin{array}{l}\text { Observer } \\
\text { t2 mean } \\
\text { and SD }\end{array}$ & $11.57(7.4)$ & $2.83(2.43)$ & $1.67(1.58)$ & $2.74(2.4)$ & $1.76(1.58)$ & $0.62(0.98)$ & $0.47(0.8)$ & $0.54(0.85)$ \\
\hline
\end{tabular}

$* * \mathrm{p}<0.001 ; * \mathrm{p}<0.005$ 
Authors' Note

We thank Professor Mark L. Howe for comments on an earlier version. 